\title{
INTEGRATION TECHNIQUES OF ALARM SYSTEMS
}

\section{Jan VALOUCH ${ }^{1}$}

\section{Review article}

\begin{tabular}{|c|c|}
\hline Abstract: & $\begin{array}{l}\text { Integration of the alarm systems is a modern way of using the current technological } \\
\text { capability elements of intruder alarm system, CCTV, access control and hold-up alarm } \\
\text { systems. These applications can be integrated with each other or supplement the non- } \\
\text { alarm systems and thereby provide the simplification of automation processes in } \\
\text { commercial and residential buildings. This article deals with the problem of the technical } \\
\text { solutions of interconnection alarm and non-alarm systems. The key output of the article is } \\
\text { the classification of the techniques of integration these systems. }\end{array}$ \\
\hline Keywords: & $\begin{array}{l}\text { Integrated alarm system, Integration, Intruder alarm system, Automation system, non - } \\
\text { alarm application. }\end{array}$ \\
\hline
\end{tabular}

\section{Introduction}

Integrated Alarm Systems are defined according to relevant technical regulation ČSN CLC/TS 50398 as systems having a one or more common devices at least one of which is an alarm application ( $\breve{C S N}$, 2009). Alarm application designed to protect life, property or environment:

- intruder and hold-up alarm system (I\&HAS),

- intruder alarm system (IAS),

- hold-up alarm system (HAS),

- social alarm system (SAS),

- closed circuit television used for security and surveillance (CCTV),

- access control system (ACS),

- fire detection and fire alarm systems (FDAS),

- environmental alarm systems and lift alarm systems.

The above systems can be integrated with each other or with non- alarm applications:

- lighting, heating, air-conditioning, ventilation,

- irrigation, building management, energy management.

Integration of alarm and non- alarm applications is solved by various technical solutions, starting with a simple connection of input/output contacts to sophisticated software solutions. In terms of needs of formulation and the subsequent drafting of an integrated alarm system (for example an Intruder alarm system complete with camera system, control systems for lighting and heating) is an important factor of the selection of the appropriate elementsmethod of the technical solutions of interconnection systems. Therefore it is necessary to categorize - to classify the different techniques of integration and to create a basic guide for the preparation of IAS implementation.

Selection of appropriate components is an important point of the system design as the first phase of the setting up the IAS, especially because of its feasibility, requirements for operation, adequacy of financing costs and particularly the possibility of any further expansion of the system. In other parts of the article, the author presents the proposal for a possible classification of technical forms of the integration of alarm and non- alarm systems.

\section{Materials and methods}

Drafting of the classification of technical methods of integration alarm and non- alarm applications based on an analysis of these document types:

- technical standards- I\&HAS, CCTV, ACCESS, SAS,

- technical product specifications,

- installation manuals of relevant systems and their elements,

- legislation - definition of technical requirements for the IAS components (Act, 1997).

The basic document in integrated alarm systems is a technical standard ČSN CLC / TS 50398 Alarm systems - Combined and integrated systems General requirements.

Although the CSN was issued as early as in 2005 and then in 2009, not many interested companies (distributors, installation companies) know this fact or have only general information about the

Tomas Bata University in Zlín, Faculty of Applied Informatics, Department of Security Engineering, Zlín, Czech Republic, valouch@fai.utb.cz 
issue of the CEN/CENELEC, which has the status of technical specifications and its acceptance by the national standards of members of the CEN/ CENELEC is not required (only as an obligation to ensure notification of the existence and availability of CLC/TS 50398). The standard solves the issue of definitions of basic terms, describe basic types of IAS configuration, system requirements, requirements for documentation and training.

Integrated alarm system has been considered with respect to document title as a synonym term to a combined and integrated alarm system, which can be misleading, because the current understanding of the term combination we mean a clustering as opposed to the term integration, which expresses the unification or jointing process to higher arrangement.

In practice, associated with the alarm systems, the difference can be illustrated quite clearly by the installation of an intruder alarm system, supplemented by a camera system, where these systems are independent of each other (combined) in contrast to the same systems that are interconnected - for example, IAS output initializes, through the alarm, the input start of individual elements of CCTV - cameras, recording devices (integration). However, with respect to the legislative texts, we will continue to speak summarily about the integrated alarm systems.

An important requirement for the integration of systems is that the application of relevant standards relates to individual applications. Each application must primarily comply with its own standards (I\&HAS, CCTV, ACCESS, SAS, see CSN 5013x series) and must meet specific requirements for system integration. Common components used under integration must then comply with all application standards in specific configuration and must be used with the strictest requirements of each of the standards related to the function of the system. The key sources of the draft techniques of integration alarm systems are primarily the technical documentation (specifications, installation manuals) of the components of alarm systems and automation systems, focusing on the features, modules, accessories and equipment relating to the implementation of integration with other applications (Jablotron, 2011; Variant, 2012; ABB, 2012).

\section{Results}

Problems of combination and integration of alarm and non- alarm applications can generally be included in the field of system integration (although this is mainly associated with information systems), which is understood as the delivery of services based on connecting heterogeneous subsystems into one functioning unit. Basic forms of system integration are shown in Fig. 1.

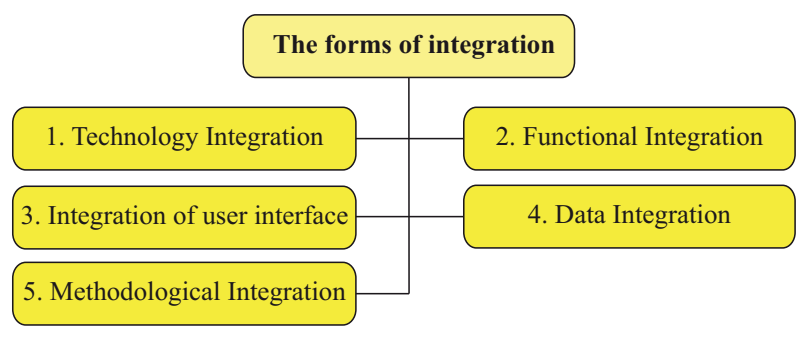

Fig. 1 The basic forms of System Integration

Integrated alarm systems can support the fulfilment of all the above types of system integration. The following Tab. 1 gives examples of Integrated alarm system applications, classified in terms of the aforementioned forms.

Tab. 1 Examples of applications of Integrated alarm systems

\begin{tabular}{|c|l|}
\hline Form & \multicolumn{1}{c|}{ Application } \\
\hline $\begin{array}{c}\text { Technology } \\
\text { Integration }\end{array}$ & $\begin{array}{l}\text { Integration I\&HAS, CCTV, ACS, SAS } \\
\text { + control of lighting, heating, blinds, air } \\
\text { conditioning. }\end{array}$ \\
\hline $\begin{array}{c}\text { Functional } \\
\text { Integration }\end{array}$ & $\begin{array}{l}\text { Integration of Access card functions: } \\
\text { Entry - Exit Registration/Registration of } \\
\text { manufacturing operations. }\end{array}$ \\
\hline $\begin{array}{c}\text { Integration of } \\
\text { user interface }\end{array}$ & $\begin{array}{l}\text { Combined control of alarm and } \\
\text { non-alarm systems - control panels, } \\
\text { applications for mobile phones, } \\
\text { technology "smart home". }\end{array}$ \\
\hline Data Integration & $\begin{array}{l}\text { SW products for the personal } \\
\text { identification, evidence of entry, } \\
\text { attendance, export to the wage systems. }\end{array}$ \\
\hline Methodological \\
Integration & $\begin{array}{l}\text { Implementation methodology of } \\
\text { registration and movement of visitors, } \\
\text { registration of persons and vehicles, } \\
\text { escorts, the presence of visitors, blocking } \\
\text { entry of undesirable persons. }\end{array}$ \\
\hline
\end{tabular}

The basis of each form of integration is always a technological solution of interconnection systems. With respect to the quantity and difference of currently available electronic devices, there are always several variants of project for a specific object (residential or commercial), which is possible to design based on the requirements of the investor. The following part of Article describes the classification of individual technical ways of integrating alarm and non-alarm applications, which is processed by analysing the provisions of the relevant technical regulations and particularly the possibility of currently used 
technologies. Technical ways of interconnecting the individual applications can be divided into the following basic groups:

- hardware methods of integration,

- software methods of integration.

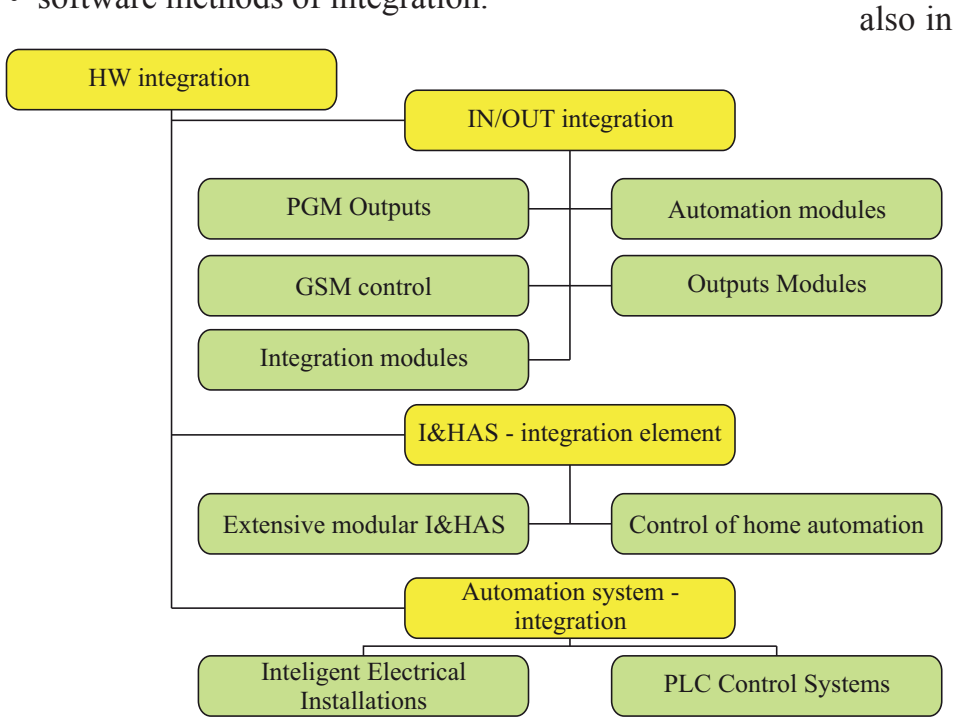

Fig. 2 Hardware methods of Integration of alarm systems

Hardware (HW) methods of integration are based on the interconnection of systems through their inputs and outputs and on the technical parameters of alarm systems, which may include, in addition to the basic security functions, also specific-expanding elements (modules) to control alarm or non-alarm applications (lighting control, heating, access control, etc.). The hardware integration methods also include the use of automation systems (e.g. intelligent wiring system), which in addition to standard control of technologies for buildings (lighting, heating, air conditioning, blinds, irrigation, sound, etc.) offer the ability to connect security devices (detectors, hold-up devices, IAS control and indicating equipment etc.). Hardware integration methods can be divided into the types listed in Fig. 2.

\section{Integration IN/OUT}

Technical systems integration solutions labelled as IN/OUT are a way of interconnection systems through their inputs and outputs. The parameters of individual components of alarm systems (e.g. control and indicating equipment, control units, access control systems, CCTV recording devices, cameras, etc.) allow to realize the integration of heterogeneous systems to ensure mutual transfer and sharing of information of the sub-systems (I\&HAS, CCTV,
ACCESS, control of lighting, heating etc.). This information is then used to control (change state) connected systems in accordance with pre-set configurations. IN/OUT integration is especially useful for small applications, but it is realizable also in larger projects. Such solutions, however, are technically demanding and limited as the maximum number of programmable outputs or the number of connectable modules. In terms of overall system design with respect to its management, control and visualization capabilities, IN/OUT is the weakest variant of integration, but due to wide possibilities of creating a concrete implementation of customer-requested features (such as turn off selected power circuits in the building after arming IAS) is a frequently used solutions (Luke, 2011). The advantages of IN/OUT integration:

- systems are not negatively affected by each other,

- failure of one application does not have an impact on other applications,

- interconnection of the systems is feasible regardless of the manufacturer and communication protocols.

On the other hand, the disadvantages of this solution can include:

- hardware requirements on the number of inputs/ outputs,

- decentralized management system,

- problematic central visualization in real time.

The following Fig. 3 shows a schema of various options of IN/OUT integration in the case, when the basic element of an integrated system is IAS control and indicating equipment.

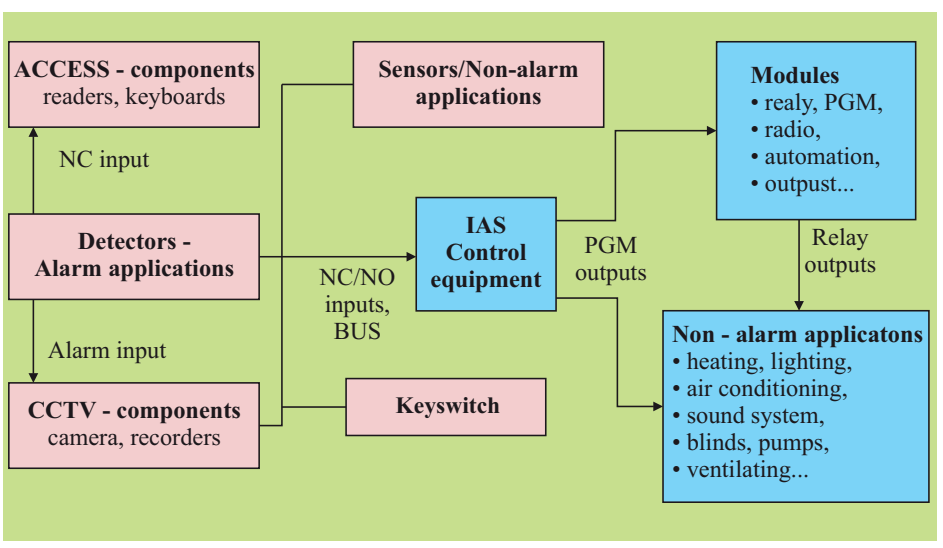

Fig. 3 Scheme of the various options of integrating IN/OUT 


\subsection{PGM outputs}

Basic way of IN/OUT integration is the use of programmable outputs - PGM of components of alarm systems, the most of IAS control and indicating equipment. PGM outputs allow the implementation of specific activities in objects turn on/off and control - lights, heating, locks, pumps, etc.) using a programmed response to a trigger (arming, disarming, tampering, intrusion, failure, activation of hold-up device etc.). PGM outputs can be activated also by key-switch zones or by standard buttons involved in $\mathrm{NC} / \mathrm{NO}$ input control equipment, expanders, card readers, etc.

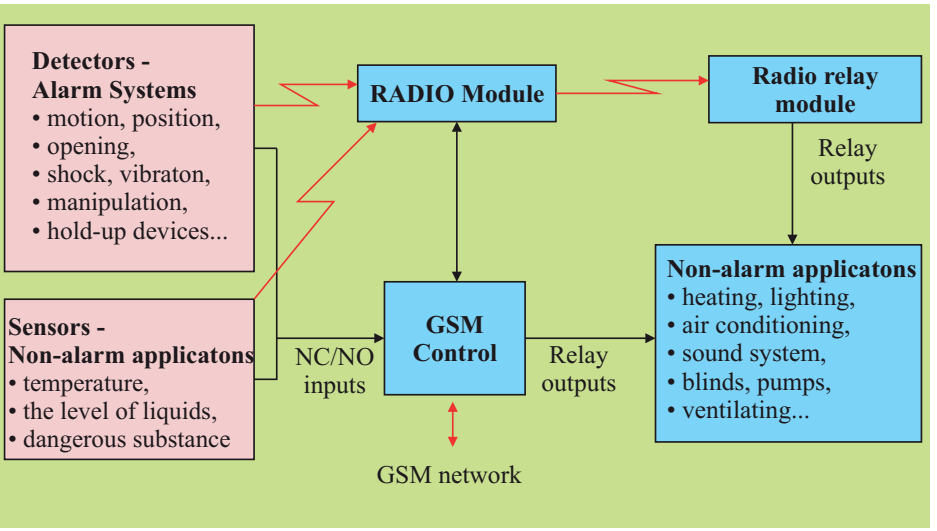

Programmable outputs allow the transmission of binary information or the control of power supply for other devices and are usually implemented as module cards of motherboards of control equipment or as individual modules. The number of separate PGM outputs of IAS control panels is usually 2 to 16 , using the expansion modules then 8 to several hundred outputs. PGM outputs are technically implemented as transistor open collector outputs (approx. 12V/150 mA), or closed-emitter (about $5 \mathrm{~V} / 1 \mathrm{~mA}$ ), or as potential less outputs relay (contacts for low voltage $30 \mathrm{~V} / 1 \mathrm{~A}$ or power voltage $250 \mathrm{~V} / 5 \mathrm{~A}$ ) or as a relay voltage outputs. Peripheral devices are connected to the PGM outputs directly or via additional relay modules for the purpose of strengthening (voltage levels, current consumption) and for galvanic separation from the controlled device.

\subsection{GSM controller}

The integration of alarm and non-alarm applications is feasible with selected functions of GSM controllers, which are independent to IAS control panel. The standard features of these products include:

- automatic SMS sending depending on the initialization events (on/off system - in connection with IAS, alarm, fault, the set level - temperature, the liquid level),

- remote control circuit output GSM controller by SMS messages or ringing,

- setting of time windows (time switch),

- control of non-alarm systems (heating, lighting, pumps, irrigation, locks ...).

Fig. 4 Scheme of the application of GSM control integration

GSM controllers usually have a lower number (approximately $4+4$ ) inputs $(\mathrm{NC} / \mathrm{NO}$ ) and outputs (relays). Outputs can be controlled remotely (GSM messages) or locally through mutual setting of bindings depending on the status of inputs. The controlled devices can be connected by wire or wirelessly, using radio modules. Schematic representation of integration capabilities using GSM controller is shown in Fig. 4.

\subsection{Automation Modules}

Simple and less extensive installation of integrated alarm systems can be realized using general-purpose automation modules. The standard application possibilities of these modules include:

- remote management, monitoring and control of connected technologies in buildings,

- creating of scheduled activities of integrated systems,

- integration with I\&HAS - status monitoring and control of basic functions (on/off),

- checking, monitoring and controlling building technologies (the level of liquids, pumps, air humidity, flue gas, control of the limit position, drying, irrigation),

- monitoring and control of unattended operation facilities (pumping stations, transformer stations),

- home automation (temperature, lighting, wells, irrigation, blinds),

- agriculture (heating, ventilation, air conditioning, feeding),

- control of entry elements (gates, doors).

Modules can be installed directly in controlled facilities and their control is usually implemented using TCP/IP traffic from any PC connected via Ethernet/Internet. Other features of automation 
modules include also the possibility to set up links between status of inputs and outputs or monitoring history events. The possibilities of integration using automation modules are shown in Fig. 5.

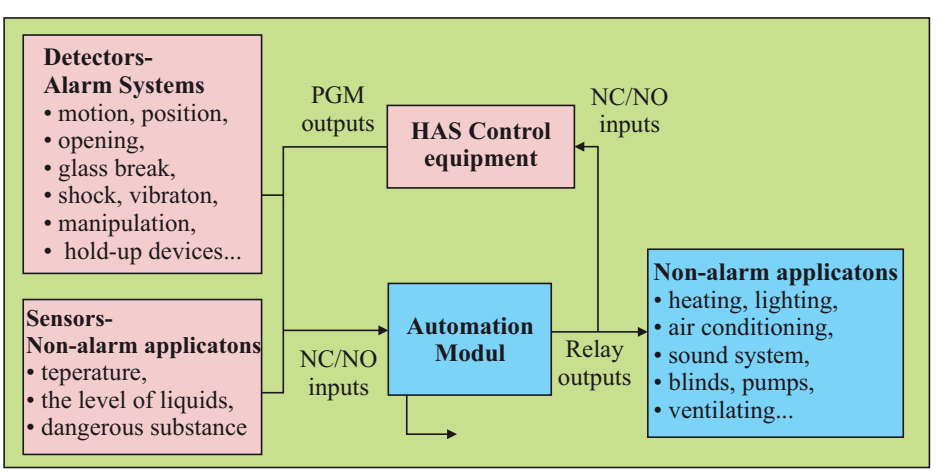

and non-alarm applications can be implemented. This control panel, in conjunction with SW product, ensures communication with the system operator and the central control and visualization of building technology. All elements of the systems modules are technologically identical, and therefore there is no compatibility issue. Central control and administration here may seem as an advantage and disadvantages at the same time. Failure of the control panel has resulted in malfunctions of most of the connected technologies. The example of the schematic of an integrated system linking with the superior I\&HAS is shown in Fig. 6. Smaller applications can be realized using control panel of IHAS, which generates

Fig. 5 Schema of the possibilities of integrating using automation modules

signals for home automation systems (such as X -10 ... control of electrical equipment signals transmitted by power lead $230 \mathrm{~V}$ ).

\subsection{Output modules}

The installation of alarm systems can include output modules, which are located directly in the box of IAS control panel. These modules are equipped with fixed programmable outputs (usually semiconductors) whose state corresponds to defined events (copies triggers - such as arming, disarming, intrusion, panic, fire, failure, power failure, the state PGM). Output module cooperates with communicators (GSM, LAN, PSTN).

\subsection{Integration modules}

Integration modules provide for selected types of control units of alarm systems such as control panel, their integration with other systems or their connection to additional software product. The module reads the conditions of control panel and allows its control while still maintaining the integrity and closure of alarm system. It usually includes parallel, serial and USB ports.

\section{Intrusion and hold-up alarm systems as the integration element}

Extensive alarm systems are based on the groups of modules that are connected to the bus. These groups include alarm components (motion detectors, opening, glass break etc.) and can also include elements of access control system and elements of automation, allowing the control of connected non-alarm technology of buildings. Control panel is the central element of the system in which the functions of access control system or other alarm

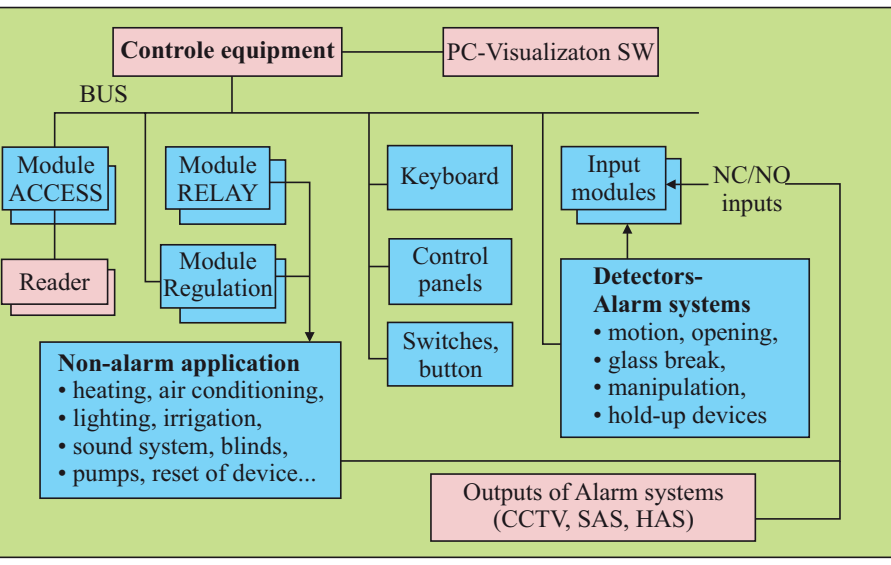

Fig. 6 Scheme of possible variants of integration with superior I\&HAS

\section{Automation system as an integration element}

Automation systems used to control the technology in buildings (lighting, heating, blinds, irrigation, etc.) contain a central control with PLC (Programmable Logic Controller) controllers and can be also used to secure the object. Modern automation systems use technology systems of intelligent wiring. These are built on the platform of the wire bus to which the sensors (temperature, humidity, buttons, microphone, detectors ...) and action elements (switches, relays, warning device ...) are connected. Individual elements of building technology (lighting, air conditioning, blinds, heating, boiler ...) can then be controlled locally, remotely (GSM, web) or can have a centrally set timetable for their activation and reciprocal links. 
IAS can be connected to the systems of intelligent wiring through a transducer, which ensures two-way transmission of signals between the IAS control panel and the control unit of wiring system, which further ensures links with other technologies in the building. When arming the system after the departure of persons from an object, the system may turn off the lights, lock the doors, or turn off selected socket circuits. In case of intrusion, the central unit can be programmed to turn on lights in the building, pull blinds etc. In another variant, it is possible to create a security system on the platform of the system of intelligent wiring without the use of IAS control panels. In this case, the detectors (motion, open, glass break, vibration, etc.) are connected to other sensors on the bus and based on an assessment of their condition, the control unit runs the program - the transmission of messages to alarm receiving centre, the activation of warning devices, etc. Such a method of security cannot be certified in accordance with the series of technical standards EN 50131.

Smaller applications can be realized with the use of PLC control systems, which are primarily designed to monitor and control of building technologies but their inputs/outputs can be connected to the relevant elements of alarm systems.

\section{Software integration}

Software (SW) integration methods are based on linking separate applications via a communication bus, and their control, management, visualization are provided by software products, which are installed on an external computer (server, client PC) or at unattended control centres equipped with the necessary software. Individual alarm/non- alarm applications can also be connected to the server via the network (LAN, WAN). For simple applications, the PC client is connected to application using a serial interface or USB port. The common element is the user access to particular functions via PC or through mobile devices.

Software products can be classified by function, which provide for the needs of installation companies but especially to ensure the needs of users with regard to connected systems. These functions involve integration of selected activities or technology, for example by creating a central database for user management, central visualization or the central setting of automatic links between connected systems. Overview of functions is listed on Fig. 7. functions in many cases. The following part of this article describes the possibilities of software in accordance with the designation under which is currently offered on the market.

\subsection{Software of control panels of alarm systems}

Additional programs delivered to the various types or line of control panel IAS providing local or remote connection panel (control unit) with a $\mathrm{PC}$ in order to realize the basic functions - programming, monitoring, evaluation and event logger. These programs serve the need for installation and service companies. Here we talk about integration from the perspective of a central evaluation and event storage of control panels, that can be hardware linked to other systems.

\subsection{Software for user administration}

These programs allow to realize custom settings control units (control panel) connected systems. In the area of security, it is usually the IAS control panel with access to control system. The user has, in addition to basic functions (evaluation, monitoring, archiving events), especially the following possibilities:

- setting up user profiles, create descriptions of subsystem zones, terminals,

- creating time schedules of access,

- allocation and registration of identifiers (cards, fingerprints),

- filtering of event history (type, time, place, person). 


\subsection{Visualization software}

Visualization programs provide, in contrast to programs for user management, other comfort function, namely transparent visualization of system status in real time. Based on the plans, ground plan of objects (buildings or outdoor space - there is also software for the visualization of perimeter protection) with a graphical showing the locations of individual components (detectors, cameras, card readers, terminals, etc.), the operator can monitor the system status and control selected functions - on/ off surveillance subsystem or zone, opening doors, turning on the camera or control PGM outputs.

\subsection{Integration software of the systems of buildings}

Interconnection of security systems and other building technology is implemented through software product, which is installed on the server and these systems are controlled by the client PC through a web browser. Individual systems are connected in a LAN. Integration software is an additional service, allowing, for example:

- setting the automatic links between systems, visualization of systems,

- local and remote control, systems management and users,

- control activities of operator,

- management of attendance in continuity to payroll system,

- definition of roles and rights of users (employee, operator, manager, receptionist, etc.).

Failure of activities of integration SW may adversely affect the functionality of connected systems. It is therefore appropriate to ensure the integration of important system bindings by hardware. Integration software usually consists of separate modules that can be combined according to customer requirements (IAS, HAS, CCTV, ACCESS, FDAS, attendance, the map interface etc.)

\subsection{The partial conclusion of software integration}

The main advantages of deploying of SW integration products include:

- ability to integrate products from different manufacturers, the implementation of on-line service,

- central control of events and alerts in the system, the central management of user data,

- obtaining before-alarm information,
- better overview of the situation in the building,

- faster response to emergency events, reducing false alarms,

- user control and operators, operative changes of system,

- standard (graphical) user interface, reducing the cost of supervision in the building, maintenance, training, human resources, expansion of the possibilities of connected devices.

\section{Conclusion}

Development of technological capabilities of systems and higher customer requirements are the basis for a wider deployment of integrated systems, containing alarm systems and other building technologies (non-alarm application). The interconnection of systems provides the users with many benefits in the form of increased security of buildings, comfort control or potential savings in energy costs and human resources. The aim of the article was to present the proposed classification of technical ways of integrating various systems to support the convergence of perspectives and approaches of professionals in this field, and especially in the design phase of integrated systems. The proposal builds on the basic dividing on hardware and software methods of connection. Hardware methods are divided into: IN/OUT Integration (PGM outputs, automation modules, integration modules, output modules, GSM controller), the integration using the superior IHAS or integration using the automation system. SW integration methods are classified according to their basic functions, which SW products can provide (integration of technology - automation of bindings, visualization, user management, supervision, evaluation and archiving of events). 


\section{References}

ABB (2011). Inteligentní elektroinstalace Ego-n: Návrhový a instalační manuál. Issue 5. [online]. Jablonec nad Nisou: ABB, 2011 [cit. 2012-01-11]. Available at: http://www117.abb.com (in Czech).

Act No 22/1997 Col. on Technical Requirements for Products and amending and supplementing certain laws (in Czech).

ČSN CLC/TS 50398:2009. Alarm systems - Combined and integrated alarm systems - General requirements (in Czech).

Jablotron Alarms (2012). Instalační manuály prvků zabezpečovacích systémů [online]. Jablonec nad Nisou: Jablotron Alarms, 2012 [cit. 2012-03-11]. Available at: http://zabezpeceni-objektu.jablotron.cz/cz/sekce/ vyrobky/ (in Czech).

JANOŠEC, Josef. Fire safety in reality (2010). TRANSACTIONS of the VŠB - Technical University of Ostrava, Safety Engineering Series. 2010, No. 1, Vol. V, p. 35 - 44. ISSN 1801-1764 (in Czech).

ŘEHÁK, David, GIERTLOVÁ, Zuzana (2011). Proposal for Unifying the Safety and Security Terminology at the Faculty of SAFETY Engineering of the VŠB - Technical University of Ostrava. TRANSACTIONS of the VŠB Technical University of Ostrava, Safety Engineering Series. 2011, No. 2, Vol. VI, p. 63 - 66. ISSN 1801-1764.

VALOUCH, Jan (2011). Security Technology, systems and management I. $1^{\text {st }}$ ed. Luděk Lukáś. Zlín: VeRBuM, 2011. Legislation of design security systems, p. 171-183. ISBN 978-80-87500-05-07 (in Czech).

Variant Plus (2012). Product Catalog 2012 - 2013. Třebíč: Variant plus, 2012. 325 p. (in Czech).

WANG, M, CUI, Y. (2010) Design and Development of Integrated Voice Alarm System. Dianli Zidonghua Shebei/ Electric Power Automation Equipment. 2010, vol. 30, no. 7, p. 124-126. ISSN: 1006-6047.

WANG, S.-S, YAN, K.-Q, WANG, S.-C, LIU, C.-W. (2011) An Integrated Intrusion Detection System for Clusterbased Wireless Sensor Networks. Expert Systems with Applications. 2011, vol. 38, no. 12, p. 15234-15243. ISSN: 0957-4174. 